\title{
ERS in Munich: going for gold!
}

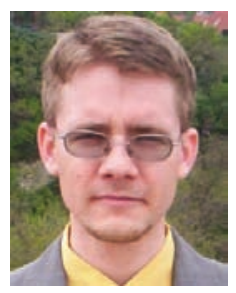

I. Ruzsics

Pécs

Hungary

E-mail: atomeger@freemail.hu
The European Respiratory Society (ERS)

Annual Congress was held this year in Munich, and I was honoured to be one of the few lucky people who received a Gold Sponsorship from the ERS, as the 1stprize winner of the HERMES (Harmonised Education in Respiratory Medicine for European Specialists) Contest.

On the first day of the Congress, September 1, 2006, I took part in two Postgraduate Courses, where I gained new insights into obstructive sleep apnoea and pulmonary rehabilitation from renowned experts in these fields. In the evening, I joined many others at the ERS Opening Ceremony, where the annual awards were presented. During the ceremony, the Bavarian spirit embraced us through the beautiful performance of the Opera Brass and the "Tölzer Knabenchor" Boys Choir.

The following day, the scientific part of the Congress began, with many symposia, hot topics, oral sessions and poster discussions, many of which I attended with the other 17,000 Congress participants. I was very pleased to have the

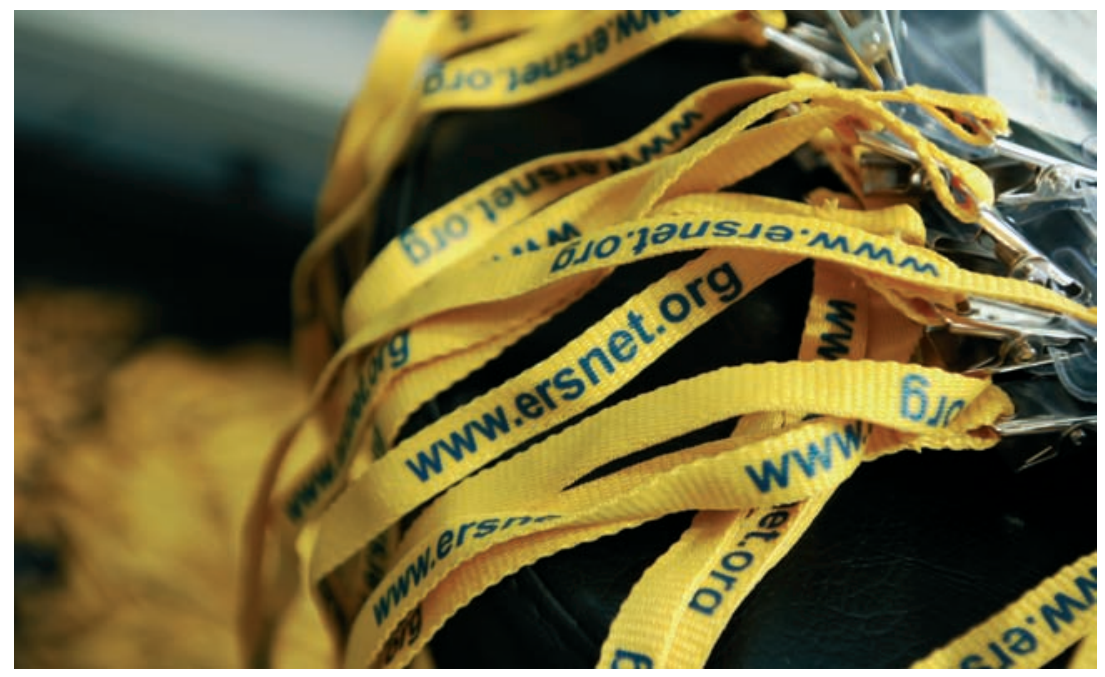

opportunity to choose to join any of the 19 sessions that were running in parallel.

The technological advances of the Congress this year were interesting for me. For the first time, the ERS introduced electronic posters, as an alternative to standard paper posters, which could be very easily accessed online. In addition, in the abstract print zone, you could print the abstracts you were interested in rather than having to carry around the bigger-than-ever abstract book. Missing a presentation was also not a problem, due to the possibility of downloading podcasts via the Internet as needed or via RSS.

Personally, it was fascinating to meet other colleagues working in respiratory medicine from all over the world, including those as far afield as Australia, Africa, Japan and India. In the National Village, one could not only get informed about other national respiratory societies but also about the nations' traditions. There were also representatives from the HERMES project, information about education of pulmonologists in the USA, and information on plans for the future training and licensing of European pulmonologists.

Luckily, I had some spare time to explore the beautiful Bavarian capital of Munich. People here were very nice, and helped the many times when I got lost. The amazing Marienplatz, the splendid churches, streets and houses, historical monuments, royal buildings, museums, the magnificient view from the Olympic Tower and the Allianz Arena were unforgettable experiences.

I would like to thank the ERS for the opportunity to go to the Congress and for the experience I obtained. For those of you who were unable to attend, I would like to suggest that you visit the ERS website to learn more about this year's Congress and to look at the opportunities for programmes and awards so that you can attend next year! 



\section{Highlights of the 16th Annual ERS Congress}

\section{New records}

The 16th Annual ERS Congress in Munich was a success with a record 17,240 participants, making it the largest respiratory meeting in the world. A record number of abstracts were also submitted and the scientific programme was of the usual high standard.

During the Congress, more than 800 participants joined the Society, setting yet another record! The total number of ERS members now stands at 8,700.

The International Congress Centre Munich was an excellent venue for the Congress, with excellent services and facilities.

\section{Bavarian spirit}

The Opening Ceremony and Welcome Reception embraced the Bavarian spirit.

During the Opening Ceremony, the Presidential Award was presented to Prof. Amund Gulsvik (Oslo, Norway) for his profound impact upon the development of respiratory epidemiology. Prof. Paul A. Vermeire (Antwerp, Belgium) received the Congress Chair Award in recognition of being a driving, force in the creation of the ERS and in the development and growth of the'European Respiratory Journal. The Educational Award was presented to Prof. John Cibson (Newcastle, UK) for his outstanding contribution to education in respiratory medicine. The European Lung Foundation Award went to Prof. Albert Osterhaus (Rotterdam, The Netherlands), one of the world's feading virologists, in recognition of his groundbreaking research, particularly in the field of aviann flu and SARS. Sf

\section{Promoting lung health}

This year's spirometry testing event, organised jointly with the member association "Deutscher Lungentag" to raise public awareness about lung health, took place in the centre of Munich at the Odeonsplatz. The perfect weather conditions and the ideal location led to more than 2,000 "healthy" people testing their lung function over the 2 days. Educational lectures on the burden of Jung diseases were also given by respiratory medical experts.-

\section{Social events}

The fantastic "Museums Night" allowed delegates exclusive admission to three famous Pinakothek Museums. It was a well-attended event, and a great way to relax and enjoy the culture Munich has to offer.

The performance of the opera Carmina Burana, composed by Carl Orff, at the Gasteig Centre, was extremely popular. The Orchestra, Choir and Soloists were joined by 200 vocalists, who produced an imposing and powerful sound.

The Speakers' Dinner was held in the historical surroundings of the oldest Munich beer cellar, the Augustiner Keller, and with accompanying Bavarian folk music.

It is hoped that the participants enjoyed their time in Munich. The timing of the Congress was ideal, following on from the World Cup that was held in Munich this summer, which resulted in a perfect infrastructure for transport, hotels and security. The ERS looks forward to seeing you again for next year's Congress in Stockholm! 